
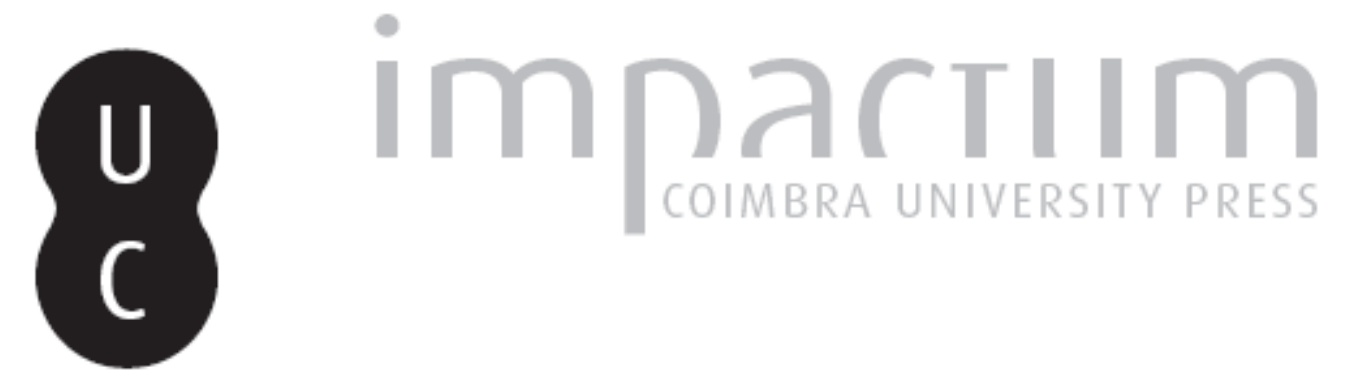

\title{
A decomposição cadavérica e as dificuldades de gestão dos espaços funerários
}

Autor(es): $\quad$ Ferreira, Maria Teresa; Cunha, Eugénia

Publicado por: Imprensa da Universidade de Coimbra

URL persistente:

URI:http://hdl.handle.net/10316.2/39077

DOI:

DOI:http://dx.doi.org/10.14195/2182-7982_31_4

Accessed : $\quad$ 26-Apr-2023 15:29:33

A navegação consulta e descarregamento dos títulos inseridos nas Bibliotecas Digitais UC Digitalis, UC Pombalina e UC Impactum, pressupõem a aceitação plena e sem reservas dos Termos e Condições de Uso destas Bibliotecas Digitais, disponíveis em https://digitalis.uc.pt/pt-pt/termos.

Conforme exposto nos referidos Termos e Condições de Uso, o descarregamento de títulos de acesso restrito requer uma licença válida de autorização devendo o utilizador aceder ao(s) documento(s) a partir de um endereço de IP da instituição detentora da supramencionada licença.

Ao utilizador é apenas permitido o descarregamento para uso pessoal, pelo que o emprego do(s) título(s) descarregado(s) para outro fim, designadamente comercial, carece de autorização do respetivo autor ou editor da obra.

Na medida em que todas as obras da UC Digitalis se encontram protegidas pelo Código do Direito de Autor e Direitos Conexos e demais legislação aplicável, toda a cópia, parcial ou total, deste documento, nos casos em que é legalmente admitida, deverá conter ou fazer-se acompanhar por este aviso.

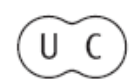




$$
\bar{A}
$$




\section{A decomposição cadavérica e as dificuldades de gestão dos espaços funerários}

\section{Maria Teresa Ferreira', Eugénia Cunha'}

mtsferreira@yahoo.com

DOI: http://dx.doi.org/10.14195/2182-7982_31_4

Resumo Compreender a decomposição cadavérica é fundamental na prática forense, nomeadamente para a estimativa do intervalo pós-morte (PMI'), sendo também relevante na gestão funerária, tarefa cada vez mais difícil devido à sobrelotação dos cemitérios dos grandes centros populacionais.

Aplicando os princípios da Tafonomia a uma amostra de 35 inumações (18 indivíduos do sexo masculino e 17 do feminino, todos adultos; PMI entre 3 e 83 anos) de dois cemitérios municipais da Figueira da Foz, analisaram-se os seguintes parâmetros:

${ }^{1}$ Usa-se a sigla em inglês por uma questão de uniformização

\footnotetext{
${ }^{1}$ Centro de Ecologia Funcional / Centro de Investigação em Antropologia e Saúde / Departamento de Ciências da Vida da Universidade de Coimbra, Coimbra, Portugal.
}

Abstract Understanding the process of decomposition is critical in forensic practice, particularly for estimating the post-mortem interval (PMI). The knowledge of this process is of paramount importance in cemetery management, particularly in cases of overcrowding of cemeteries.

Applying the principles of Taphonomy to a sample of 35 burials ( 18 males and 17 females, all adults; PMI from 3 to 83 years) of two municipal cemeteries in Figueira da Foz, we analysed the following parameters: decomposition, skeletal preservation, PMI, type and composition of the grave, age-atdeath and sex of the individual. 
decomposição cadavérica, preservação esquelética, PMI, tipo e composição da sepultura, idade e sexo do indivíduo.

Este estudo mostrou que houve variações no desenrolar do processo de decomposição dos cadáveres analisados, dos quais 14 sofreram fenómenos de preservação (2 mumificaram e 10 saponificaram). A decomposição depende do PMl, mas esta relação é variável e não linear, tornando impossível prever o estado de decomposição do cadáver apenas com base no PMI de forma a programar devidamente as exumações/trasladações necessárias à gestão dos espaços funerários. Tornou-se evidente que o prazo legal de 3 anos é insuficiente para a rotação das sepulturas. Observou-se também que o tipo de sepultura, o vestuário e a presença de fralda tiveram influência na decomposição dos cadáveres.

Palavras-chave: Antropologia forense; gestão de cemitérios; decomposição cadavérica; intervalo pós-morte (PMI).

\section{Introdução}

O entendimento dos processos de decomposição cadavérica é essencial para a interpretação de um contexto com restos humanos, quer seja arqueológico (permitindo a compreensão dos gestos funerários dos nossos antepassados), quer seja um caso forense (fundamental na reconstituição dos
This study showed that there were variations in the course of the decomposition of the individuals analysed, of which 14 were preserved (two mummified and ten saponified). The decomposition is dependent on the PMI, but this relationship is variable and non-linear, making it impossible to predict the state of decomposition of the cadaver only based on the PMI in order to properly programme the necessary exhumations for the management of funerary spaces. It became apparent that the legal period of three years is insufficient for the rotation of the graves. It was also observed that the type of grave, clothing and the presence of diapers influenced the decomposition of corpses.

\section{Keywords: Forensic anthropology; cemetery} management; decomposition; post-mortem interval (PMI).

acontecimentos peri e post motem e na estimativa do PMI) (Ferreira, 2012). Como se irá mostrar com este trabalho, a compreensão dos processos de decomposição é igualmente pertinente na gestão funerária dos cemitérios atuais.

A gestão funerária dos cemitérios nem sempre é uma tarefa fácil. Os cemitérios públicos existem em Portugal há quase dois séculos. As normas para 
a sua construção ficaram estabelecidas pelo Decreto 44 220, de 3 de Março de 1962, referindo, entre outros, as condições do solo, que, segundo o decreto, deverá impedir a contaminação dos lençóis de água e impedir as emanações de vapores decorrentes da decomposição, permitindo a lenta decomposição dos cadáveres (cf. Nascimento e Trabulo, 2008). Todavia, atualmente várias são as entidades municipais que se deparam com o grave problema de sobrelotação dos cemitérios sob sua tutela, sobretudo nos grandes centros urbanos (Durães et al., 2010; Ferreira e Cunha, 2013). Apesar de a lei referir que se pode proceder à exumação após três anos, raros são os casos em que os cadáveres apresentam as condições de esqueletização necessárias para tal acontecer, impedindo a reutilização dos covais (Ferreira, 2012).

Por isso, é indispensável estudar o desenrolar do processo de decomposição dos cadáveres inumados nos cemitérios de modo a criar um corpus documental que permita encontrar soluções práticas e ambientalmente responsáveis a aplicar. São, pois, necessários estudos para melhor se conhecer a influência das variáveis extrínsecas ao cadáver no processo de decomposição dos indivíduos sepultados nos cemitérios portugueses.

No presente artigo, apresenta-se um estudo levado a cabo em dois cemitérios da Figueira da Foz, no âmbito do projeto de doutoramento da primeira autora, onde se acompanhou, com a de- vida autorização, a abertura dos covais durante os processos de exumação e trasladação dos restos esqueléticos por motivos de gestão rotineira dos cemitérios.

A Câmara Municipal da Figueira da Foz tem sob sua tutela dois cemitérios. O Cemitério Setentrional é um antigo cemitério do século XIX, onde a maioria das inumações foi realizada em jazigos utilizando caixões de chumbo. O Cemitério Oriental é o atualmente utilizado e tem duas áreas com características distintas. Uma área original do cemitério onde os covais foram abertos no solo argiloso e colmatados com os sedimentos daí retirados. Outra, mais recente, na qual os talhões foram abertos com covais com paredes em tijolo e colmatados com areia. A heterogeneidade das inumações ali encontradas ilustra as condições de vários cemitérios nacionais, tornando a Figueira da Foz um excelente caso de estudo.

Com esta análise pretendeu-se avaliar as condições de inumação com o objetivo de melhor compreender o processo de decomposição cadavérica e sugerir modificações dos procedimentos de enterramento de forma a acelerar a decomposição, contribuindo assim para a redução da sobrelotação de alguns cemitérios nacionais. 


\section{Material}

Entre setembro de 2009 e julho de 2012, observámos 35 exumações nos dois cemitérios municipais da Figueira da Foz, 31 no Cemitério Oriental e quatro no Cemitério Setentrional. A origem sepulcral desta amostra é diversa: dois dos quatro indivíduos observados no Cemitério Setentrional encontravam-se em jazigo, depositados em antigos caixões de chumbo, enquanto os outros dois estavam inumados em sepulturas de terra. Também no Cemitério Oriental houve heterogeneidade, quer no tipo de sepultura, quer no tipo de caixão, bem como no tipo de tratamento a que o cadáver foi submetido, tendo sido ainda observadas quatro exumações de ossários individuais.

A amostra é composta por 35 indivíduos adultos, com idades à morte compreendidas entre os 30 e os 97 anos ( $\bar{x}$ $=74,46$ anos; D.P. 17,224), dos quais 18 $(51,4 \%)$ do sexo masculino e $17(48,6 \%)$ do feminino. A data da morte variou entre 1927 e 2009, traduzindo-se num PMI entre os 3 os 83 anos, sendo de destacar que $40 \%$ ( $n=14$ ) têm um PMI superior a 20 anos. A cada indivíduo foi atribuído um número sequencial precedido pelo acrónimo CFFoz. As informações relativas a cada indivíduo (identificação do coval, sexo, idade à morte, data da morte e/ou da inumação) foram obtidas através dos registos camarários e das lápides das sepulturas. A identidade dos indivíduos não foi registada.
A amostra dos CFFoz divide-se em duas subamostras: a dos indivíduos que foram efetivamente exumados e trasladados $(21 ; 60,0 \%)$ (tabela 1); e outra composta por indivíduos cujos cadáveres não se encontravam esqueletizados, não se tendo, por isso, concluído a exumação (14; 40,0\%) (tabela 2).

Tabela 1. Lista de indivíduos dos CFFoz que foram exumados

\begin{tabular}{|c|c|c|c|}
\hline N. ${ }^{\circ}$ registo & Sexo & Idade à morte & PMI (anos) \\
\hline 1 & $\mathrm{~F}$ & 89 & 9 \\
\hline 3 & M & 63 & 17 \\
\hline 6 & M & 75 & 14 \\
\hline $8^{*}$ & M & 81 & 43 \\
\hline $9^{*}$ & $\mathrm{~F}$ & 68 & 41 \\
\hline 10 & M & 69 & 22 \\
\hline 11 & M & 78 & 26 \\
\hline 13 & M & 59 & 65 \\
\hline 14 & $\mathrm{~F}$ & 85 & 34 \\
\hline 16 & $\mathrm{~F}$ & 70 & 6 \\
\hline 18 & M & 73 & 29 \\
\hline 24 & M & 68 & 18 \\
\hline 25 & $\mathrm{~F}$ & 61 & 27 \\
\hline 26 & M & 77 & 8 \\
\hline 27 & M & 71 & 7 \\
\hline 28 & $\mathrm{~F}$ & 91 & 22 \\
\hline 29 & $\mathrm{~F}$ & 85 & 9 \\
\hline 30 & $\mathrm{~F}$ & 97 & 13 \\
\hline 31 & M & 94 & 16 \\
\hline 32 & $\mathrm{~F}$ & 91 & 14 \\
\hline 33 & M & 85 & 35 \\
\hline
\end{tabular}

* Indivíduos do Cemitério Setentrional M - Masculino; F - Feminino 
Tabela 2. Lista de indivíduos dos CFFoz que não foram exumados

\begin{tabular}{cccc}
\hline N. ${ }^{\circ}$ registo & Sexo & Idade à morte & PMI (anos) \\
\hline 2 & $\mathrm{~F}$ & 83 & 16 \\
4 & $\mathrm{~F}$ & 76 & 7 \\
$5^{*}$ & $\mathrm{M}$ & 80 & 61 \\
$7^{*}$ & $\mathrm{M}$ & 30 & 83 \\
12 & $\mathrm{~F}$ & 86 & 27 \\
15 & $\mathrm{~F}$ & 30 & 3 \\
17 & $\mathrm{M}$ & 80 & 20 \\
19 & $\mathrm{~F}$ & 81 & 4 \\
20 & $\mathrm{~F}$ & 94 & 8 \\
21 & $\mathrm{M}$ & 55 & 20 \\
22 & $\mathrm{~F}$ & 72 & 21 \\
23 & $\mathrm{M}$ & 31 & 16 \\
34 & $\mathrm{~F}$ & 89 & 9 \\
35 & $\mathrm{M}$ & 89 & 9 \\
\hline
\end{tabular}

* Indivíduos do Cemitério Setentrional; M - Masculino; F - Feminino

\section{Métodos}

A abertura da sepultura foi feita pelos coveiros. Após atingirem o caixão, este foi aberto, removendo-se a tampa e afastando-se as mortalhas que envolviam o cadáver. Sempre que possível, descemos ao interior da sepultura para uma observação mais próxima das condições do cadáver. Quando este ainda não se encontrava completamente esqueletizado, o coval era novamente tapado. Nos casos em que já estava esqueletizado, os restos ósseos eram exumados. Os ossos eram separados das peças de vestuário e recolhidos. As condições de preservação dos restos esqueléticos e o vestuário e calçado foram assinalados. Todo o procedimento foi fotografado.

Para além das anotações descritivas e do preenchimento dos esquemas ilustrativos do estado de preservação esquelética, esta foi avaliada para cada tipo de osso e/ou região anatómica - os parâmetros gerais de preservação estabelecidos no método descrito em Ferreira (2012): crânio, face, mandíbula, vértebras cervicais, torácicas e lombares, sacro, costelas, escápulas, ossos ilíacos, úmeros, fémures, tíbias, tarsos, clavículas, rádios, ulnas e fíbulas. A avaliação de diferentes regiões de um mesmo osso foi feita para seis tipos de osso: escápulas; ossos ilíacos; úmeros; fémures; tíbias; e calcâneos. $\mathrm{O}$ índice de preservação geral (IPG) do esqueleto foi calculado com base nos 29 parâmetros gerais de preservação (cf. Ferreira, 2012; Ferreira e Cunha, 2012).

A análise do sedimento de oito sepulturas do Cemitério Ocidental foi autorizada. Durante a exumação, foi recolhida uma amostra de $100 \mathrm{~g}$ de solo próximo dos restos humanos. A análise da textura e a avaliação do grau de compacidade de cada amostra foi efetuada por um geoarqueólogo (Luís Almeida - Grupo Dryas Octopetala). A medição do pH foi realizada seguindo a especificação LNEC E-203 (1967) e recorrendo ao medidor EcoSense pH100 YSI. 


\section{Resultados}

\section{Cemitério Setentrional}

Os quatro cadáveres observados no Cemitério Setentrional foram os que tinham um PMI mais elevado, superior a 40 anos. Dois indivíduos foram exumados de um mesmo coval escavado diretamente no solo argiloso (CFFoz.8 - ossário, e (FFoz.9), encontrando-se completamente esqueletizados, sem restos de tecidos moles ou gorduras, com a superfície óssea a escamar e as extremidades dos ossos longos erodidas e com exposição do tecido trabecular. Os outros dois casos reportam-se a inumações em caixões de chumbo. A exumação de CFFoz.5 ocorreu com o intuito de se proceder à sua trasladação para outro cemitério. Aquando do falecimento, em 1949, o defunto foi deposto num primeiro caixão de madeira, vestido com camisa, fato de fazenda e botas em pele. O cadáver foi coberto por uma mortalha sobre a qual colocaram uma camada de cal. O primeiro caixão de madeira foi encerrado num caixão de chumbo e este colocado dentro de um segundo caixão de madeira. Foi depositado no jazigo familiar construído em betão, a cerca de 2 $m$ de profundidade. Apesar de terem decorrido 61 anos desde a morte, o cadáver apresentava-se em excelente estado de preservação, completamente mumificado (mumificação natural), permitindo inclusivamente a identificação por traços fisionómicos faciais, uma das vantagens deste estado de preservação. No outro caso (CFFoz.7), a exumação ocorreu para se proceder à troca de caixões, uma vez que a integridade do caixão se encontrava comprometida. Também este indivíduo foi inumado com fato completo, sobre as várias mortalhas do caixão e estava mumificado (mumificação natural).

\section{Cemitério Oriental da Figueira da Foz}

O Cemitério Oriental da Figueira da Foz oferece várias soluções de deposição de cadáveres, sendo que, destas, assistimos à abertura de 31 sepulturas de dois tipos: sepulturas escavadas diretamente na matriz silte-argilosa (18; 58,07\%); e covais construídos com paredes de tijolo de cerâmica e colmatados com areia (13; 41,93\%). O sedimento deste cemitério é de matriz silte-argilosa, com incorporação de grãos de dimensão variável e com um grau moderado de compacidade e de porosidade. Nos novos talhões, os covais são colmatados com areia fina não cimentada e não compactada, de composição quártzica, com graus de rolamento e de calibragem moderados. As cinco amostras de argila recolhidas apresentaram um $\mathrm{pH}$ alcalino $(\bar{x}=8,24$; D.P. 0,06261). As três amostras de areia mostraram valores de $\mathrm{pH}$ semelhantes $(\bar{x}$ =8,20; D.P. 0,05508). Os 31 cadáveres examinados no Cemitério Oriental tinham 
Tabela 3. Estado de decomposição dos 35 indivíduos da amostra de CFFoz, por zona corporal (n)

\begin{tabular}{lccccc}
\hline Estado de Decomposição & \multicolumn{5}{c}{ Zona corporal } \\
& cabeça & tórax & abdómen & $\begin{array}{c}\text { membros } \\
\text { superiores }\end{array}$ & $\begin{array}{c}\text { membros } \\
\text { inferiores }\end{array}$ \\
\hline Putrefação & $1(2,9 \%)$ & $2(5,7 \%)$ & $2(5,7 \%)$ & $1(2,9 \%)$ & $1(2,9 \%)$ \\
Mumificação & $2(5,7 \%)$ & $2(5,7 \%)$ & $2(5,7 \%)$ & $2(5,7 \%)$ & $2(5,7 \%)$ \\
Saponificação & $4(11,4 \%)$ & $8(22,9 \%)$ & $10(28,6 \%)$ & $5(14,3 \%)$ & $5(14,3 \%)$ \\
Esqueletização parcial & $3(8,6 \%)$ & $6(17,1 \%)$ & $4(11,4 \%)$ & $2(5,7 \%)$ & $2(5,7 \%)$ \\
Esqueletização completa & $25(71,4 \%)$ & $17(48,6 \%)$ & $17(48,6 \%)$ & $25(71,4 \%)$ & $25(71,4 \%)$ \\
\hline
\end{tabular}

um PMI médio de 17,8 anos (D.P. 12,315), variando entre 3 e 65 anos. Reportavam-se a 15 homens $(48,4 \%)$ e 16 mulheres (51,6\%), com idades à morte entre os $30 \mathrm{e}$ os 97 anos. Destes, 19 (61,3\%) foram efetivamente exumados, enquanto $12(38,7 \%)$ não exibiam as condições de esqueletização necessárias para a exumação.

\section{A amostra de CFFoz}

A maioria dos defuntos $(27 ; 87,1 \%)$ foi inumada vestida, em caixões de madeira com mortalhas de tecidos sintéticos. Em três casos $(9,7 \%)$, nem o caixão nem o vestuário foram observados - eram "ossários" (CFFoz.13, CFFoz.24 e CFFoz.33), ou seja, indivíduos exumados anteriormente e cujos ossos foram arrumados numa das extremidades do coval. Os seus restos esqueléticos mostravam-se fragmentados, com a camada superficial do osso a escamar e o tecido trabecular exposto. Um indivíduo, embalsamado, foi inumado num caixão metálico, distinto dos comummente utilizados em Portugal (o cadáver provinha do estrangeiro), cujo interior estava revestido de mortalhas de tecido acetinado (CFFoz.23). Os órgãos internos estavam em putrefação, com acentuada perda do volume corporal e perda de líquidos. Devido ao estado de putrefação, a trasladação não teve lugar. A presença/ausência de fralda' foi possível de indagar em 28 indivíduos, estando presente em 12 cadáveres.

Os cadáveres encontraram-se em diversos estádios de decomposição. A cabeça e os membros superiores e inferiores eram as zonas corporais com maior percentagem de esqueletização completa $(71,4 \%)$ (tabela 3). Dois indivíduos $(5,7 \%)$ estavam mumificados (CFFoz.5 e CFFoz.7), um em putrefação (CFFoz.23), e

É habitual os cadáveres serem inumados com fralda para conter fezes e urina que podem ser expelidas durante as cerimónias fúnebres, nomeadamente no velório. É comummente referido que a sua presença atrasa o processo de decomposição da região abdominal e pélvica. 
outro com o tórax e o abdómen também em putrefação (CFFoz.21). Apenas em quatro $(11,4 \%)$ a cabeça surgiu saponificada (tal como o todo o corpo: CFFoz.15, CFFoz.17, CFFoz.34 e (FFoz.35), mas o abdómen foi assim encontrado em 10 $(28,6 \%)$ dos casos.

Os indivíduos com zonas anatómicas saponificadas exibiam diferentes tipos de adipocera. Nos quatro casos de cadáveres totalmente saponificados, a adipocera era húmida, de textura mole e tonalidade clara, em tons de amarelo, e com forte odor a amoníaco. Noutros casos (CFFoz.2, CFFoz.19 e CFFoz.20), a adipocera estava menos húmida do que a referida anteriormente e a sua textura era mais dura e com uma tonalidade amarela-escura. Noutros indivíduos (CFFoz.4, CFFoz.12 e CFFoz.22), já com a cabeça e os membros esqueletizados, a adipocera apresentava-se em forma de duras placas, de tons que variavam do branco acinzentado ao cinzento-escuro, secas, inodoras, que se soltavam facilmente dos ossos adjacentes.

Os cadáveres completamente saponificados tinham uma adipocera húmida, de textura mole e tonalidade amarela-clara, e com forte odor a amoníaco, mas as semelhanças entre eles terminam aqui. $\mathrm{O}$ mais recente, com $\mathrm{PMI}$ de 3 anos, era uma mulher jovem (CFFoz.15), de constituição física normal, cuja causa de morte se relacionou com uma doença oncológica, inumada num coval de areia húmida, no Verão, e com um vestido de noiva de mangas e saia comprida. Outro, um homem idoso (CFFoz.17) de constituição física e causa de morte desconhecidas, inumado em novembro num coval de argila, vestindo fato completo, e com um PMI bastante superior, de 20 anos. Os restantes casos de adipocera foram observados em mulheres idosas. Em três casos, a adipocera estava menos húmida do que nos anteriores, com textura mais dura e de cor amarelo-escuro. Estes indivíduos foram inumados com vestidos, roupa interior em renda sintética (incluindo a vulgarmente designada "combinação"), collants e com fralda. Dois deles (com tórax e abdómen saponificados) foram inumados no mesmo coval de areia húmida, com diferentes PMI e estádios de decomposição da cabeça e membros (CFFoz.19: 4 anos, cabeça e membros parcialmente esqueletizados; CFFoz.20: 8 anos, cabeça e membros completamente esqueletizados). O terceiro caso (CFFoz.2), uma mulher obesa, inumada num coval de argila, tinha um PMI de 16 anos, portanto superior ao dos casos anteriores, estando o crânio parcialmente esqueletizado e o resto do corpo saponificado. Nos indivíduos CFFoz.4, CFFoz.12 e CFFoz.22, já com a cabeça e os membros esqueletizados, a adipocera apresentava-se em forma de placas secas, duras e quebradiças, de tons entre o branco-acinzentado e o cinzento-escuro, inodoras, que se soltavam facilmente 
Tabela 4. Análise de Qui-quadrado para o estado de decomposição das várias zonas corporais em função da idade à morte para a amostra de CFFoz

\begin{tabular}{|c|c|c|c|c|c|}
\hline & Zona corporal & $\mathrm{n}$ & $X^{2}$ & $\mathrm{gl}$ & $\mathrm{p}$ \\
\hline \multirow{5}{*}{ 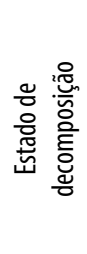 } & cabeça & 35 & 26,636 & 20 & 0,146 \\
\hline & tórax & 35 & 34,593 & 20 & 0,022 \\
\hline & abdómen & 35 & 33,944 & 20 & 0,027 \\
\hline & membros superiores & 35 & 26,390 & 20 & 0,153 \\
\hline & membros inferiores & 35 & 26,390 & 20 & 0,153 \\
\hline
\end{tabular}

Tabela 5. Análise de Qui-quadrado para o estado de decomposição das várias zonas corporais em função do sexo para a amostra de CFFoz

\begin{tabular}{|c|c|c|c|c|c|}
\hline & Zona corporal & $\mathrm{n}$ & $X^{2}$ & gl & $\mathrm{p}$ \\
\hline \multirow{5}{*}{ 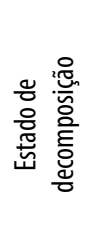 } & cabeça & 35 & 3,347 & 4 & 0,501 \\
\hline & tórax & 35 & 7,173 & 4 & 0,127 \\
\hline & abdómen & 35 & 8,637 & 4 & 0,071 \\
\hline & membros superiores & 35 & 3,214 & 4 & 0,523 \\
\hline & membros inferiores & 35 & 3,214 & 4 & 0,523 \\
\hline
\end{tabular}

dos ossos adjacentes. Todos foram enterrados em covais de argila. O CFFoz.4, obeso, foi inumado no Verão, vestindo camisa, vestido e collants, e com fralda. Os CFFoz.12 e CFFoz.22 foram inumados no início do Outono, mas, se o indivíduo CFFoz.22 mostrava apenas um vestido de tecido leve, o CFFoz.12 tinha várias peças de roupa (mas sem fralda): casaco de malha sintética, vestido de fazenda, roupa interior em renda sintética ("combinação"), collants e sem fralda.

Não foram observadas diferenças estatisticamente significativas entre o estado de decomposição das várias zo- nas corporais em função da idade à morte ou do sexo (tabelas 4 e 5). O estado de decomposição do abdómen não se mostrou dependente da presença/ausência de fralda. Não se encontrou significância estatística para o estado de decomposição das várias zonas corporais em função do PMI (tabela 6). No entanto, nota-se que quanto maior o PMI, maior o número de indivíduos com a cabeça e os membros esqueletizados, sendo que com PMI superior a 20 anos todos os indivíduos, exceto os dois mumificados, mostravam estas zonas corporais completamente esqueletizadas. 
Tabela 6. Análise de Qui-quadrado para o estado de decomposição das várias zonas corporais em função do PMI para a amostra de CFFoz

\begin{tabular}{|c|c|c|c|c|c|}
\hline & Zona corporal & $\mathrm{n}$ & $X^{2}$ & $g l$ & $\mathrm{p}$ \\
\hline \multirow{5}{*}{ 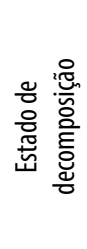 } & cabeça & 35 & 86,197 & 92 & 0,661 \\
\hline & tórax & 35 & 88,487 & 92 & 0,584 \\
\hline & abdómen & 35 & 91,480 & 92 & 0,496 \\
\hline & membros superiores & 35 & 89,017 & 92 & 0,569 \\
\hline & membros inferiores & 35 & 89,017 & 92 & 0,569 \\
\hline
\end{tabular}

\section{A subamostra dos indivíduos não exumados}

A subamostra dos não exumados é constituída por seis indivíduos do sexo masculino $(42,9 \%)$ e oito do feminino $(57,1 \%)$, com idades à morte entre os 30 e os 94 anos ( $\bar{x}=69,71$ anos; D.P. 23,253), dos quais dois procedem de jazigos do Cemitério Setentrional (CFFoz.5 e CFFoz.7) e os restantes 12 de sepulturas em argila (7; 50\%) e em areia (5; 35,7\%) do Cemitério Oriental. A data da morte varia entre 1927 e 2007, traduzindo-se por um PMI entre 3 e 83 anos ( $\bar{x}=21,71$ anos; D.P. 22,855), respetivamente (cf. tabela 2). Nesta subamostra reduzida, o estado de decomposição por zona corporal é diverso. A cabeça e os membros surgem completamente esqueletizados em 35,7\% dos casos, ou parcialmente esqueletizados (14,3\% e $7,1 \%$, respetivamente). O abdómen estava saponificado na maioria dos indivíduos (71,4\%). A mumificação registou-se em dois casos (CFFoz.5 e CFFoz.7).

\section{A subamostra dos indivíduos exumados}

A subamostra dos exumados é constituída por 21 indivíduos, 12 homens $(57,1 \%)$ e 9 mulheres $(42,9 \%)$, falecidos entre os 59 e os 97 anos ( $\bar{x}=77,62$ anos; D.P. 11,254$)$, dos quais $95,2 \%$ (20) pereceram com mais de 60 anos, sendo, portanto, maioritariamente idosos. A morte ocorreu entre 1945 e 2004, traduzindo-se num PMl entre 6 e 65 anos ( $\bar{x}=22,62$ anos; S.D. 14,743).

Dois indivíduos desta subamostra foram exumados de um coval escavado na matriz argilosa do Cemitério Setentrional (CFFoz.8 e CFFoz.9), e os restantes 19 de sepulturas em argila $(11 ; 57,9 \%)$ e em areia $(8 ; 42,1 \%)$ do Cemitério Oriental.

A preservação desta amostra esquelética não era boa, com metade das regiões observadas com percentagens de classificação "completo" inferiores a 50\% (tabela 7). O osso mais bem preservado era a mandíbula, completa em $76,2 \%$ dos indivíduos. O osso coxal e as costelas têm a maior taxa de fragmentação $(81,0 \%)$, 
Tabela 7. Preservação geral dos indivíduos da subamostra dos exumados de CFFoz

\begin{tabular}{|c|c|c|c|c|}
\hline $\begin{array}{l}\text { Tipo de osso/ } \\
\text { região anatómica }\end{array}$ & & $\begin{array}{l}\text { Completo } \\
\text { n (\%) }\end{array}$ & $\begin{array}{c}\text { Fragmentado } \\
n(\%)\end{array}$ & $\begin{array}{c}\text { Ausente } \\
\mathrm{n}(\%)\end{array}$ \\
\hline Crânio & & $12(57,1 \%)$ & $9(42,9 \%)$ & 0 \\
\hline Face & & $12(57,1 \%)$ & $8(38,1 \%)$ & $1(4,8 \%)$ \\
\hline Mandíbula & & $16(76,2 \%)$ & $5(23,8 \%)$ & 0 \\
\hline \multirow{3}{*}{ Vértebras } & Cervicais & $14(66,7 \%)$ & $6(28,6 \%)$ & $1(4,8 \%)$ \\
\hline & Torácicas & $8(38,1 \%)$ & $11(52,4 \%)$ & $2(9,5 \%)$ \\
\hline & Lombares & $10(47,6 \%)$ & $10(47,6 \%)$ & $1(4,8 \%)$ \\
\hline Sacro & & $6(28,6 \%)$ & $14(66,7 \%)$ & $1(4,8 \%)$ \\
\hline Costela & & $4(19,0 \%)$ & $17(81,0 \%)$ & 0 \\
\hline Escápula & & $5(23,8 \%)$ & $14(66,7 \%)$ & $2(9,5 \%)$ \\
\hline Clavícula & & $11(52,4 \%)$ & $10(47,6 \%)$ & 0 \\
\hline Úmero & & $11(52,4 \%)$ & $9(42,9 \%)$ & $1(4,8 \%)$ \\
\hline Rádio & & $9(42,9 \%)$ & $11(52,4 \%)$ & $1(4,8 \%)$ \\
\hline Ulna & & $11(52,4 \%)$ & $10(47,6 \%)$ & 0 \\
\hline Osso coxal & & $3(14,3 \%)$ & $17(81,0 \%)$ & $1(4,8 \%)$ \\
\hline Fémur & & $10(47,6 \%)$ & $10(47,6 \%)$ & 0 \\
\hline Tíbia & & $10(47,6 \%)$ & $10(47,6 \%)$ & 0 \\
\hline Fíbula & & $8(38,1 \%)$ & $11(52,4 \%)$ & $1(4,8 \%)$ \\
\hline Tarso & & $12(57,1 \%)$ & $7(33,3 \%)$ & $1(4,8 \%)$ \\
\hline
\end{tabular}

seguidos da escápula e do sacro. Estes ossos, além de muito fragmentados, foram encontrados deformados. Por exemplo, a zona púbica do osso coxal surgia frequentemente dobrada sobre a região do isquíon, no sentido da superfície interna do osso. Curiosamente, os ossos da face mostravam uma preservação idêntica à dos da calote craniana, apesar de mais frágeis e de se encontrarem numa posição superior dentro da sepultura. As vértebras cervicais são a zona da coluna vertebral melhor preservada. Os ossos longos mostram resultados semelhantes entre si, com as extremidades repetidamente fragmentadas ou mesmo ausentes, sendo o úmero e a ulna os mais bem preservados $(52,4 \%)$ e a fíbula o mais mal preservado (38,1\%). Não se notam grandes diferenças entre a preservação dos ossos longos dos membros superiores e dos inferiores. 
Tabela 8. Parâmetros particulares de preservação da subamostra dos exumados de CFFoz

\begin{tabular}{|c|c|c|c|c|}
\hline Tipo de osso & Zona anatómica & $\begin{array}{c}\text { Completo } \\
\mathrm{n}(\%)\end{array}$ & $\begin{array}{c}\text { Fragmentado } \\
\mathrm{n}(\%)\end{array}$ & $\begin{array}{c}\text { Ausente } \\
\mathrm{n}(\%)\end{array}$ \\
\hline \multirow{4}{*}{ Escápula } & Ângulo inferior & $4(20,0 \%)$ & $13(65,0 \%)$ & $3(15,0 \%)$ \\
\hline & Processo coracoide & $6(30,0 \%)$ & $10(50,0 \%)$ & $4(20,0 \%)$ \\
\hline & Acrómio & $6(30,0 \%)$ & $12(60,0 \%)$ & $2(10,0 \%)$ \\
\hline & Ramo ascendente do acrómio & $8(40,0 \%)$ & $10(50,0 \%)$ & $2(10,0 \%)$ \\
\hline \multirow{4}{*}{ Osso coxal } & Crista ilíaca & $10(50,0 \%)$ & $8(40,0 \%)$ & $2(10,0 \%)$ \\
\hline & Isquíon & $9(45,0 \%)$ & $8(40,0 \%)$ & $3(15,0 \%)$ \\
\hline & Púbis & $2(10,0 \%)$ & $13(65,0 \%)$ & $5(25,0 \%)$ \\
\hline & Superfície retroauricular & $9(45,0 \%)$ & $9(45,0 \%)$ & $2(10,0 \%)$ \\
\hline \multirow{4}{*}{ Úmero } & Cabeça & $11(52,4 \%)$ & $8(38,1 \%)$ & $2(9,5 \%)$ \\
\hline & Superfície proximal lateral & $12(57,1 \%)$ & $8(38,1 \%)$ & $1(4,8 \%)$ \\
\hline & Epicôndilo medial & $16(76,2 \%)$ & $4(19,0 \%)$ & $1(4,8 \%)$ \\
\hline & Epicôndilo lateral & $16(76,2 \%)$ & $4(19,0 \%)$ & $1(4,8 \%)$ \\
\hline \multirow{4}{*}{ Fémur } & Cabeça & $12(63,2 \%)$ & $7(36,8 \%)$ & 0 \\
\hline & Grande trocânter & $11(55,0 \%)$ & $9(45,0 \%)$ & 0 \\
\hline & Côndilo medial & $12(60,0 \%)$ & $6(30,0 \%)$ & $2(10,0 \%)$ \\
\hline & Côndilo lateral & $12(60,0 \%)$ & $6(30,0 \%)$ & $2(10,0 \%)$ \\
\hline \multirow{4}{*}{ Tíbia } & Superfície anterior proximal & $10(50,0 \%)$ & $9(45,0 \%)$ & $1(5,0 \%)$ \\
\hline & Superfície posterior proximal & $10(50,0 \%)$ & $9(45,0 \%)$ & $1(5,0 \%)$ \\
\hline & Maléolo & $12(60,0 \%)$ & $7(35,0 \%)$ & $1(5,0 \%)$ \\
\hline & Superfície lateral distal & $13(65,0 \%)$ & $6(30,0 \%)$ & $1(5,0 \%)$ \\
\hline \multirow{2}{*}{ Calcâneo } & Superfície lateral & $11(55,0 \%)$ & $8(40,0 \%)$ & $1(5,0 \%)$ \\
\hline & Superfície medial & $15(75,0 \%)$ & $4(20,0 \%)$ & $1(5,0 \%)$ \\
\hline
\end{tabular}

Seis peças ósseas em cada esqueleto foram objeto de uma análise mais detalhada. Para cada uma delas avaliámos o estado de preservação de determinadas regiões anatómicas (tabela 8 ). As escápulas, mal preservadas, apresentam os piores valores, com as quatro regiões muito fragmentadas e mesmo algumas ausen- tes (percentagem de regiões ausentes entre $10,0 \%$ a 25,0\%). Para o osso coxal, também registámos algumas regiões ausentes, sobretudo a púbis, que é também a zona mais fragmentada (60,0\%) de todas as seis peças ósseas avaliadas. O úmero é o osso com os melhores resultados, sendo os epicôndilos as regiões 
mais bem preservadas (76,2\%). As regiões selecionadas para o fémur e para a tíbia mostram uma preservação fraca, mas ainda assim melhor do que a da escápula e do osso coxal, cujas formas irregulares e falta de tecido ósseo cortical certamente contribuíram para a sua má preservação. No calcâneo, a superfície lateral está mais mal preservada do que a medial, mostrando-se muito erodida, com exposição do tecido trabecular.

De um modo geral a preservação é fraca. Quando observadas em detalhe, a maioria das peças apresenta resultados igualmente fracos, mostrando-se as várias regiões anatómicas de cada osso regra geral fragmentadas ou com a superfície erodida.

Após os resultados acima descritos, não será de estranhar os encontrados depois de calculado o IPG, com um valor médio de 46,90 (D.P. 10,667; Min. 29 e Max. 67), indicativo de uma preservação fraca. Os indivíduos CFFoz.6 e CFFoz.26 tinham uma preservação excelente. Outros três indivíduos (15,0\%) mostravam uma preservação boa (CFFoz.1, CFFoz.27 e CFFoz.31) e dois (10,0\%) uma preservação razoável (CFFoz.29 e CFFoz.30). Os indivíduos CFFoz.13 e CFFoz.14 estavam incompletos e mal preservados. Os restantes onze $(55,0 \%)$ tinham uma preservação fraca. Não se encontrou significância estatística para o IPG em função do PMI.

\section{Discussão}

Nos CFFoz, encontrámos cadáveres em estádios de decomposição diversos. Os indivíduos observados provinham de dois cemitérios, de diferentes jazigos e talhões, tinham um PMI diversificado e haviam sido inumados em diferentes tipos de caixão. Observámos três indivíduos cujas características de inumação eram distintas dos restantes: CFFoz.23, embalsamado e em caixão metálico; CFFoz.5 e CFFoz.7, em antigos caixões de chumbo depositados em jazigos.

Não há dados para discutir o estado de decomposição do indivíduo CFFoz.23 pois desconhece-se qual o procedimento utilizado no processo de embalsamamento.

Na literatura, refere-se que a mumificação natural dos tecidos moles ocorre quando o ambiente envolvente é particularmente seco e arejado (Haglund, 1991; Clark et al., 1997; DiMaio e DiMaio, 2001; Carter e Tibbett, 2008). No caso dos indivíduos CFFoz.5 e CFFoz.7 é de supor que o seu encerramento em caixões de chumbo tenha provocado um ambiente seco e anaeróbico, mas não arejado. Também se considera que temperaturas extremas, de calor ou de frio, facilitam o processo de mumificação (Haglund, 1991; Clark et al., 1997; DiMaio e DiMaio, 2001; Carter e Tibbett, 2008), o que não seria de esperar no caso da Figueira da Foz, que é caracterizada por um clima 
mediterrânico (Ferreira, 2012). A escassez de flora bacteriana aeróbica pode favorecer a mumificação (Pinheiro, 2006), o que deve ter ocorrido nestes casos devido ao ambiente anaeróbico do interior dos caixões. A ausência de obesidade é tida como um fator intrínseco que favorece a mumificação (DiMaio e DiMaio, 2001; Pinheiro, 2006), o que efetivamente se pode suspeitar pela análise dos cadáveres e do vestuário. De facto, a observação da farda militar do CFFoz.5 e do fato completo do CFFoz.7 sugere uma constituição física magra de ambos os indivíduos. De salientar ainda o PMI bastante elevado. Porém, a literatura acerca da cronologia da mumificação natural é escassa, não estando ainda suficientemente documentada (Pinheiro, 2006).

Com exceção dos três indivíduos representados por "ossários", os restantes haviam sido inumados em caixões comuns de madeira e MDF. Esses três indivíduos (CFFoz.13, CFFoz.24 e CFFoz.33) encontraram-se obviamente já esqueletizados, com os ossos fragmentados e a escamar, desconhecendo-se o tipo de caixão onde foram inumados.

Os restantes cadáveres apresentavam-se em variados estados, incluindo a esqueletização total ou parcial e outros completamente saponificados (figura 1).

A literatura refere que, com o passar dos anos, a adipocera, inicialmente de tonalidade amarelada e textura mole e húmida, fica progressivamente dura, quebradiça e de tonalidade escura (Forbes, 2008; Ubelaker e Zarenko, 2011). De facto, encontrámos vários tipos de adipocera nos cadáveres de CFFoz, mas sem relação aparente com o PMI. Ou seja, indivíduos com tipos de adipocera semelhantes têm PMI diferentes e para PMI semelhantes o tipo de adipocera é distinto. A formação da adipocera pode ter sido influenciada pela ação conjunta de diversos fatores, como o sexo, o vestuário, a presença de fralda, a inumação em caixão, o tipo de solo. Porém, não se encontrou uma diferença estatisticamente significativa para o estado de decomposição do abdómen em função do sexo, da idade ou mesmo do PMI.

Apesar da variabilidade observada, o estado de decomposição de cada zona corporal parece estar diretamente dependente das restantes zonas. De facto, 12 indivíduos (34,3\%) mostram diferenças no estado das diferentes zonas corporais, sendo que dos restantes $(65,7 \%)$ 1 foi embalsamado (CFFoz.23), 2 mumificaram naturalmente (CFFoz.5 e CFFoz.7), 4 estavam saponificados (CFFoz.15, CFFoz.17, CFFoz.34 e CFFoz.35) e 16 exumaram-se completamente esqueletizados. Salienta-se aqui o baixo número de casos analisados nos CFFoz ( $n=35$ ).

Nos casos descritos, o vestuário pode ter atuado como facilitador da formação da adipocera. Os cadáveres tinham geralmente muita roupa, havendo mesmo um caso com um vestido de noiva. Ape- 


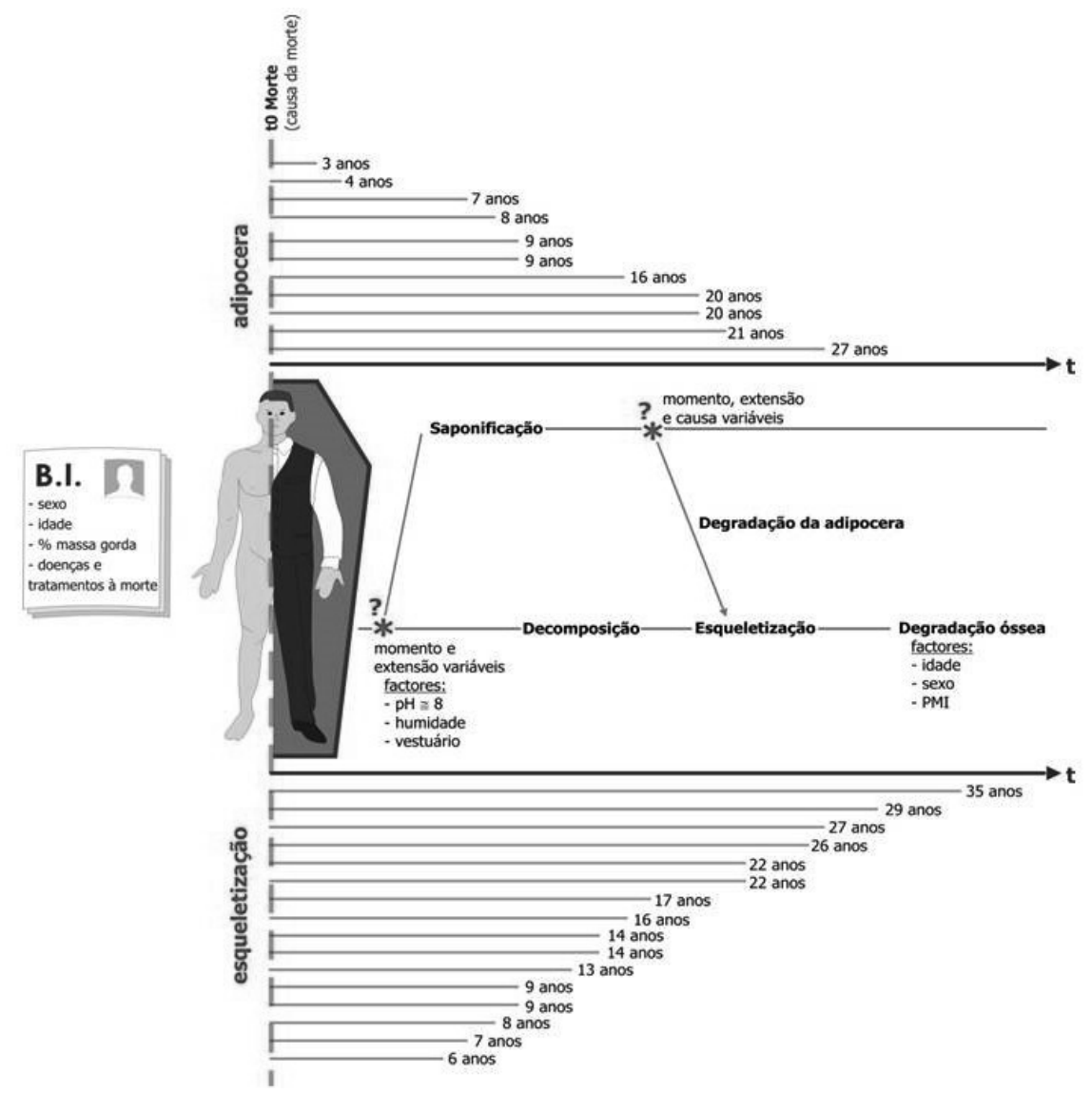

Figura 1. Estado de alguns cadáveres observados no Cemitério Oriental de CFFoz e fatores tafonómicos (excluíram-se os indivíduos em ossário e o embalsamado).

sar de não se ter realizado uma análise à composição dos tecidos, a observação do tipo de vestuário e o seu estado de preservação sugere tratar-se sobretudo de tecidos sintéticos que favorecem a saponificação (Clark et al., 1997; Gill-King, 1997; Manhein, 1997; Forbes et al., 2005a). Fibras sintéticas como o nylon resistem ao ambiente de decomposição e enterramento, não sendo atacadas por bolores, fungos ou larvas, atuando como uma barreira protetora do cadáver (Janaway, 2002; 2008). No entanto, o vestuário dos indivíduos esqueletizados e efetivamente exumados não é distinto do descrito para os casos saponificados: os homens habitualmente de fato e as muIheres com vestidos, roupa interior sintética (incluindo a "combinação") e collants. As exceções são os indivíduos CFFoz.8, 
encontrado apenas com meias e sapatos, e CFFoz.9, CFFoz.25 e CFFoz.28, todos do sexo feminino e apenas com collants, desconhecendo-se assim o tipo de vestuário mortuário utilizado. Outra peça constituída sobretudo por compostos sintéticos é a fralda. Estas são bastante resistentes, tendo-se encontrado bem preservadas, e têm na sua composição poliéster, que não só permite as reações químicas causadoras da saponificação, como também o endurecimento da adipocera (Gill-King, 1997; Forbes et al., 2005a). Ao contrário do que esperávamos (e para incredulidade dos coveiros), a análise estatística mostrou que o estado de decomposição do abdómen não está dependente da presença/ausência da fralda, estando esta também presente em cadáveres com o abdómen total ou parcialmente esqueletizado.

O tipo de solo pode favorecer a formação de adipocera. Rodriguez (1997) refere que solos argilosos são facilitadores da saponificação, o que pode ter ocorrido nalguns dos casos apresentados. Porém, os trabalhos experimentais de Forbes e colegas (2005b) e de Durães e colegas (2010) demonstraram que este não é o único tipo de solo a facilitar a formação de adipocera, podendo esta ocorrer em solos arenosos e húmidos, como nos casos dos indivíduos CFFoz.15, CFFoz.19, CFFoz.20, CFFoz.34 e CFFoz.35. Relembra-se as condições do solo mais favoráveis à formação de adipocera: temperatura (não ocorre a temperaturas inferiores a 4 ${ }^{\circ} \mathrm{C}$ e superiores a $40^{\circ} \mathrm{C}$ ), ambiente anaeróbico, $\mathrm{pH}$ ideal de 8,5 e humidade (Moses, 2012). Todos estes requisitos existem nos solos do Cemitério Oriental de onde provêm os casos de adipocera. Tanto nos covais de argila como nos de areia, os sedimentos estavam húmidos (mesmo nas exumações observadas durante o Verão), e o seu pH está próximo do ideal: valores médios de 8,24 para as argilas e de 8,20 para as areias.

Não obstante as condições dos covais favorecerem a saponificação, em vez da esqueletização, a maioria dos indivíduos foi encontrada já esqueletizada.

A preservação óssea é fraca. Se o $\mathrm{pH}$ do solo, ligeiramente alcalino, deveria favorecer a preservação óssea (Dent et al., 2004), desconhecemos qual a influência do vestuário. Por outro lado, a humidade dos sedimentos pode ter sido um fator negativo na preservação, acelerando a descalcificação da matriz óssea (Henderson, 1987). Mesmo os ossos com formas mais regulares e maior porção de tecido cortical, como o úmero, o fémur e a tíbia, foram encontrados fragmentados em metade dos indivíduos. Ainda assim, as suas percentagens de preservação são superiores às dos ossos de forma irregular, como os coxais ou as costelas. A forma das peças ósseas é um fator intrínseco que condiciona a sua preservação: ossos com formas regulares encontram-se mais bem preservados do 
que outros com formas irregulares, que tendem a deformar-se e a fragmentar-se com a pressão dos sedimentos envolventes (Henderson, 1987). Isto parece ser o que aconteceu com a zona púbica do osso coxal, que surgia dobrada sobre a região do isquíon, no sentido da superfície interna do osso. A densidade, proporção entre osso cortical e trabecular, é também um fator intrínseco ao osso e depende de fatores intrínsecos e extrínsecos ao indivíduo (Henderson, 1987; Galloway, 1997; Schultz, 1997). A densidade varia ao longo do esqueleto, sendo que ossos longos, como o úmero, o fémur e a tíbia, por serem mais densos, preservam-se melhor do que outras peças como o sacro (com maior proporção de tecido trabecular). Apesar da fraca preservação de peças ósseas de grandes dimensões, com formas regulares ou normalmente mais densas, as restantes porções ósseas foram encontradas ainda em piores condições, com os coxais, as escápulas e as costelas, ossos com pouco tecido cortical e de formas bastante irregulares, a mostrarem a pior preservação.

Sabe-se que a idade tem uma forte influência na densidade óssea, sobretudo nas mulheres pós-menopausa (Henderson, 1987; Curate, 2011). A composição etária desta pequena subamostra, composta por indivíduos idosos, pode pois ter contribuído para a fraca preservação observada. No que concerne ao sexo, os indivíduos masculinos apresentavam vá- rios estados de preservação esquelética, desde casos com IPG excelente até outros incompletos e mal preservados. Nenhum dos indivíduos do sexo feminino apresentava um IPG excelente e a maioria tinha um IPG fraco ou incompleto e mal preservado. O passar dos anos parece ter contribuído para a degradação óssea. De facto, todos os indivíduos com PMI superior a 15 anos mostravam um IPG fraco, exceto dois, ainda em piores condições, com PMI superior a 25 anos e IPG incompleto e mal preservado, ou seja com o esqueleto fragmentado, com a superfície óssea com erosão e exfoliação. Os indivíduos com PMI inferior a 15 anos apresentavam IGP excelente, bom ou razoável.

A legislação portuguesa permite a exumação de cadáveres e a sua trasladação para ossário (ou cremação) no caso de haver esqueletização completa do cadáver (Decreto-Lei n.o 411/98, de 30 de Dezembro, modificado pelo Decreto-Lei n. 5/2000, de 29 de Janeiro². Com este enquadramento legal, vários são os cemitérios onde, devido à saturação dos espaços sepulcrais, se procede regularmente à exumação e trasladação dos restos esqueléticos, libertando assim covais para novas inumações. Mesmo nas sepulturas familiares privadas há a necessidade recorrente de se realizarem

2 Cf. Nascimento e Trabulo (2008) para uma contextualização abrangente da legislação portuguesa referente ao ordenamento e questões jurídicas dos cemitérios. 
exumações para o enterramento de outro membro da família (neste caso, os cadáveres já esqueletizados dos indivíduos anteriormente inumados são "arrumados" dentro da sepultura ou enterrados a uma maior profundidade). Estes dois tipos de exumação (não judiciais) podem ser levadas a cabo três anos após a morte. No entanto, como se pode constatar pelos resultados observados, este período é claramente insuficiente, dificultando assim a gestão dos cemitérios que se encontram sobrelotados. Por outro lado, o facto de a legislação prever a possibilidade de exumação após apenas três anos pode criar falsas expectativas, quer aos familiares (que necessitam de inumar outro ente querido), quer aos municípios (que anseiam por vagar covais).

As sepulturas não parecem reunir as condições necessárias a uma rápida esqueletização, pelo contrário, os seus sedimentos reúnem as condições necessárias para a formação de adipocera. Alterações na composição dos sedimentos usados no interior das sepulturas, como as sugeridas por Durães et al. (2010) poderão contribuir para acelerar a esqueletização dos cadáveres, sendo de evitar os solos que apresentam grande percentagem de argilas e pouco porosos, com grande capacidade de retenção de águas.

A boa preservação das peças de vestuário, das fraldas e dos tecidos usados nos caixões sugere que a sua presença poderá ter contribuído para a formação de adipocera e para o retardamento da esqueletização. Mudar comportamentos não é tarefa fácil nem rápida, sobretudo quando associados a um momento tão doloroso como a morte de um ente querido. Porém, seria importante que os cadáveres fossem inumados com pouca roupa e que esta fosse confecionada com materiais biodegradáveis. A utilização de materiais biodegradáveis no fabrico dos caixões, tanto no tratamento e acabamento das madeiras como nas mortalhas dos acolchoados interiores, deverá também contribuir para uma esqueletização mais rápida. Estas alterações no vestuário e nos caixões, além de permitirem uma reutilização mais rápida dos covais e a consequente diminuição da sobrelotação de um cemitério, terão certamente um menor impacto ambiental.

\section{Conclusão}

Do exposto ao longo do presente artigo, depreendem-se as dificuldades sentidas pelas entidades gestoras dos cemitérios. Deduz-se que, face às características funerárias das inumações e das sepulturas observadas, o tempo regulamentado para proceder à exumação de cadáveres (três anos) é claramente insuficiente. Futuras alterações na composição dos sedimentos e no tipo de caixão e vestuário mortuário utilizado 
contribuirão, sem dúvida, para prevenir a formação de adipocera e acelerar o processo de decomposição, facilitando assim a gestão dos cemitérios com problemas de sobrelotação. A utilização de materiais biodegradáveis no fabrico de caixões e na roupa do cadáver pode facilitar o processo de decomposição. É relevante aferir as características do solo que facilitam a decomposição e dificultam a formação da adipocera, ou seja, qual o pH e a porosidade do solo ideais, mas que sejam soluções práticas e ambientalmente responsáveis a aplicar nos cemitérios portugueses.

\section{Agradecimentos}

As autoras agradecem ao Município da Figueira da Foz pela autorização concedida para desenvolver este trabaIho, bem como a todos os funcionários com quem tivemos o privilégio de trabaIhar, em particular o Sr. Jorge Alves, pelo apoio e disponibilidade.

As autoras agradecem igualmente à Ana Eduarda Silva (Sensebloom, Grupo Dryas Octopetala) pelo trabalho de design na figura apresentada neste artigo.

Este artigo resulta de parte do trabalho de investigação desenvolvido no âmbito da tese de Doutoramento em Antropologia forense de uma das autoras (Ferreira, 2012), com financia- mento da Fundação para a Ciência e a Tecnologia (Bolsa de Investigação SFRH/ BD/40565/2007).

\section{Referências bibliográficas}

Carter, D. O.; Tibbett, M. 2008. Cadaver decomposition and soil: processes. In: Tibbett, M.; Carter, D.O. (eds.) Soil analysis in forensic Taphonomy: Chemical and biological effects of buried human remains. Boca Raton, CRC Press: 29-52.

Clark, M. A.; Worrell, M. B.; Pless, J. E. 1997. Postmortem changes in soft tissues. In: Haglund, W. D.; Sorg, M. H. (eds.) Forensic Taphonomy: the postmortem fate of human remains. Boca Raton, CRC Press: 151-164.

Curate, F. 2011. O Perímetro do Declínio: osteoporose e fracturas de fragilidade em três amostras osteológicas identificadas portuguesas - séculos XIX \& XX. Tese de Doutoramento em Antropologia Biológica, Faculdade de Ciências e Tecnologia, Universidade de Coimbra.

DiMaio, V. J;; DiMaio, D. 2001. Forensic Pathology. 2nd edition. Boca Raton, CRC Press. Dent, B. B.; Forbes, S. L.; Stuart, B. H. 2004. Review of human decomposition processes in soil. Environmental Geology, 45: 576-585.

Durães, N.; Cortez, D.; Algarra, M.; Sánchez, F. G.; Rodríguez-Borges, J. E.; Bobos, l.; Silva, J. E. 2010. Comparison of adipocere formation in four soil types of the 
Porto (Portugal) district. Forensic Sciencelnternational, 195: 168.e1-168.e6.

Ferreira, M. T. 2012. Para lá da morte: Estudo tafonómico da decomposição cadavérica e da degradação óssea e implicações na estimativa do intervalo pós-morte. Tese de Doutoramento em Antropologia Forense, Faculdade de Ciências e Tecnologia, Universidade de Coimbra.

Ferreira, M. T.; Cunha, E. 2012. Será credível estimar o PMl em restos cadavéricos em avançado estado de decomposição? Cadernos do GEEvH [Online], 1(2): 7-20. Disponível em: http://geevh.jimdo.com/cadernos-do-geevh/arquivo-archive/vol-1-2.

Ferreira, M. T.; Cunha, E. 2013. Can we infer post mortem interval on the basis of decomposition rate? A case from a Portuguese cemetery. Forensic Science International, 226: 298.e1-298.e6. DOI: 10.1016/j.forsciint.2013.01.006

Forbes, S. L. 2008. Decomposition chemistry in a burial environment. In: Tibbett, M.; Carter, D. O. (eds.) Soil analysis in forensic Taphonomy: Chemical and biological effects of buried human remains. Boca Raton, CRC Press: 203-223.

Forbes, S. L.; Stuart, B. H.; Dent, B. B. 2005a. The effect of the method of burial on adipocere formation. Forensic Science International, 154: 44-52.

Forbes, S. L.; Dent, B. B.; Stuart, B. H. 2005b. The effect of soil type on adipocere formation. Forensic Science International, 154: 35-43.

Galloway, A. 1997. The process of decomposition: a model from the Arizona-
Sonoran desert. In: Haglund, W. D.; Sorg, M. H. (eds.) Forensic Taphonomy: the postmortem fate of human remains. Boca Raton, CRC Press: 139-150.

Gill-King, H. 1997. Chemical and ultrastrutural aspects of decomposition. In: Haglund, W. D.; Sorg, M. H. (eds.) Forensic Taphonomy: the postmortem fate of human remains. Boca Raton, CRC Press: 93-108.

Haglund, W. D. 1991. Applications of taphonomic models to forensic investigations. PhD Dissertation in Anthropology, University of Washington, Ann Arbor, UMI Dissertation Services.

Henderson, J. 1987. Factors determining the state of preservation of human remains. In: Boddington, A.; Garland, A. N.; Janaway, R. C. (eds.) Death, decay and reconstruction: approaches to archaeology and forensic science. Manchester, Manchester University Press: 43-54.

Janaway, R. C. 2002. Degradation of clothing and other dress materials associated with buried bodies of archaeological and forensic interest. In: Haglund, W. D.; Sorg, M. H. (eds.) Advances in Forensic Taphonomy: method, theory, and archaeological perspectives. Boca Raton, CRC Press: 379-402.

Janaway, R. C. 2008. The decomposition of materials associated with buried cadavers. In: Tibbett, M.; Carter, D. O. (eds.) Soil analysis in forensic Taphonomy: Chemical and biological effects of buried human remains. Boca Raton, CRC Press: 153-201. 
LNEC E-203. 1967. Solos: Determinação do pH. Especificações. Lisboa, Laboratório Nacional de Engenharia Civil.

Manhein, M. H. 1997. Decomposition rates of deliberate burials: a case study of preservation. In: Haglund, W. D.; Sorg, M. H. (eds.) Forensic Taphonomy: the postmortem fate of human remains. Boca Raton, CRC Press: 469-481.

Moses, R. J. 2012. Experimental adipocere formation: implications for adipocere formation on buried bone. Journal of Forensic Science, 57: 589-595.

Nascimento, E.; Trabulo, M. 2008. Cemitérios, ordenamentos e questões jurídicas. 3. ${ }^{\text {a }}$ edição. Coimbra, Almedina.

Pinheiro, J. 2006. Decay Process of a Cadaver. In: Schmit, A.; Cunha, E.; Pinheiro, J. (eds.) Forensic Anthropology and Medicine: Complementary sciences from recovery to cause of death. Tottowa, Human Press: 85-116.

Rodriguez, W. C. 1997. Decomposition of buried and submerged bodies. In: Haglund, W. D.; Sorg, M. H. (eds.) Forensic Taphonomy: the postmortem fate of human remains. Boca Raton, CRC Press: 459-467.

Schultz, M. 1997. Microscopic structure of bone. In: Haglund, W. D.; Sorg, M. H. (eds.) Forensic Taphonomy: the postmortem fate of human remains. Boca Raton, CRC Press: 187-199.

Ubelaker, D. H.; Zarenko, K. M. 2011. Adipocere: What is known after over two centuries of research. Forensic Science International, 208: 167-172. 